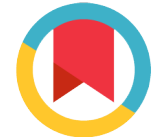

Check for updates

\title{
Blood lactate level in Elite boy swimmers after lactate tolerance exercise test
}

\section{Asghar Nikseresht ${ }^{1}$, Iman Yabande ${ }^{2}$, Karamatollah Rahmanian ${ }^{2, *}$, Abdolreza Sotoodeh Jahromi ${ }^{3}$}

*For correspondence:

rahmaniank47@yahoo.com

Competing interests: The authors declare that no competing interests exist.

Received: 26 Feb 2017

Accepted: 11 May 2017

Published: 22 May 2017

Copyright The Author(s) 2017. This article is published with open access by BioMedPress (BMP).

This article is distributed under the terms of the Creative Commons Attribution License (CC-BY 4.0)

which permits any use, distribution, and reproduction in any medium, provided the original author(s) and the source are credited.

\section{Abstract}

Introduction: To avoid injuries during high-intensity sports training, it is important to recognize conditions of bodily consumption and production of adequate energy; exercise increases the concentration of the blood lactate. This paper is an attempt to compare pre and post lactate tolerance exercise test - blood lactate concentrations - of elite boy swimmers. Methods: Blood lactates are measured by an enzymatic method on 12 subjects 30 minutes before and adjust and 24 hours after the test. Results: The mean lactate concentration of $30.35 \pm 12.16 \mathrm{mg} / \mathrm{dl}$ is observed in swimmers 30 minutes before the test. Swimmers adjust after the test show mean blood lactate concentration of $108.52 \pm 18.17 \mathrm{mg} / \mathrm{dl}$ that is significantly higher than 30 minutes before the test $(p<0.001)$. Then blood lactate level decreases below baseline level at 24 hours after the test. Conclusion: Blood lactate increases with the test and decreases below baseline within 24 hours after the test.

\section{Keywords}

Lactate Tolerance Test, Swimmer, Blood lactate, Male 


\section{Introduction}

During high-intensity sports training, it is important to recognize in what conditions the body consumes and produces adequate energy to avoid injuries. Exercise increases the concentration of the blood lactate. Additionally, blood lactate is related to intensity (Rogatzki et al., 2014; Vescovi et al., 2011) and distance of exercise (Keskinen et al., 2007; Vescovi et al., 2011). Issurin et al (Issurin et al., 2001) has found that the highest level of lactate concentrations is formed during butterfly swimming, followed by other styles including breaststroke, backstroke and freestyle swimming indicated by three different tests with 22 highly trained swimmers (14 male, 8 females) as subjects. The blood lactate significantly increased with the gradually enhanced achievement (LI, 2010). Conversely, Halfslder et al reported that the mean blood lactate concentration decreased in longer distance of swimming (Holfelder et al., 2013). In another study conducted by Sawka et al (Sawka et al., 1979), swimmers in the 200-yd butterfly, back, breast and freestyle races had similar mean blood lactate concentrations (ranging from 16.4-20.6 mm/l).

Blood lactate level was significantly increased immediately after 3 exercises and returned to the basic level within the next 3 hours (Zaree and Yarahmadi, 2013). The results showed that the plasma lactate concentration increased immediately after the exercise in comparison to former results - 24 hours after exercise - at all levels of intensity (Sholi et al., 2015). Rogatzki et al reported that blood ammonium and lactate seemed to accumulate in response to an increasing number of repetitions with decreasing rest time between sets (Rogatzki et al., 2014). Bonifazi et al showed that the post-competition blood lactate concentrations were higher in the main competitions than in the preparatory competitions (Bonifazi et al., 2000). Altimari (Altimari et al., 2010) suggested that increasing the swimming distance significantly decreased the mean speed $(p<0.01)$. The mean blood lactate concentration $7 \mathrm{~min}$ after the induction of acidosis during the lactate minimum test was $10.79 \pm 1.65 \mathrm{~mm} / \mathrm{l}$ (Altimari et al., 2010). Gorostiaga et al (Gorostiaga et al., 2014) used leg press exercise to examine blood lactate and ammonia and muscle lactate. Thirteen men participated and 1 repetition maximum leg press strength $199 \pm 33 \mathrm{~kg}$ performed either 5 sets of 10 repetitions to failure $(5 \times 10 \mathrm{RF})$, or 10 sets of 5 repetitions not to failure $(10 \times 5 \mathrm{RNF})$ with the same initial load (10RM) and interset rests ( 2 minutes) on 2 separate sessions in random order. The $5 \times 10 R F$ resulted in significant high levels of muscle lactate $(25.0 \pm 8.1 \mathrm{mmol} / \mathrm{kg}$ wet weight), blood lactate $(10.3 \pm 2.6 \mathrm{mmol} / \mathrm{L})$, and blood ammonia $(91.6 \pm 40.5$ $\mu \mathrm{mol} / \mathrm{L}$ ). During $10 \times 5 \mathrm{RNF}$ no or minimal changes were observed (Gorostiaga et al., 2014).

Lactic acid was not a waste material after anaerobic exercise, on the other hand it was such a vital, energetic substrate for oxidization (Hashimoto and Brooks, 2008). Thus, a high glycolytic capacity might mean that a player could produce more lactate to perform high-intensity exercise and could use the lactate for 
oxidation by continuing to exercise at a high level of intensity. Muscle cells had 2 major functions including the production and clearance of lactate, and blood lactate levels changed as a result of a balance between production and clearance.

Blood lactate measurement was a classical method for many decades (Beneke et al., 2011; Devlin et al., 2014). Generally, blood lactate was increased with exercise intensity (Aguiar et al., 2015; Benelli et al., 2007) which showed a clear transition from aerobic activity to anaerobic activity (Aguiar et al., 2015). In details, blood lactate was increased slowly at the beginning and then elicited an exponential rise during graded incremental exercise. For now, lactate accumulated as it was produced much faster than its decomposition. Baron et al in a 2 hour swimming test showed that capillary lactate concentration decreased significantly between 10th to 20th minute after the test (Baron et al., 2005).

The aim of present study was to compare blood lactate thirty minutes before and just and twenty-four hours after the lactate tolerance exercise test.

\section{Materials - Methods}

Twelve male swimmers who were members of the Fars Province team with at least 5-10 years of experience, agreed to participate in this study. They were between 14 and 18 years old. Swimmers were informed about the experimental procedure and of the potential risks and benefits of the study. Swimming players signed written consent for participation. The present study was approved by the Human Ethics Committee of the Jahrom University of Medical Sciences (JUMS.REC.1393.016).

After a resting of 24 hours, a self-selected warm-up swim was done. Then swimmers performed Lactate Tolerance Exercise Test (LTET) which included an $800 \mathrm{~m}$ swim with higher than threshold intensity during eight times using a normal diving start at 1-min intervals. The test was performed in a 50-m indoor pool.

Blood samples were collected from the subjects 3 times in total; that is, 30 minutes before and just and 24 hours after trial set. Blood lactate levels were analyzed by ELIZA and auto-analyzer instrument.

The Kolmogorov-Smirnov test was applied for testing each variable's normality. To compare the study variables (blood lactate before and after LTET), we used Pair $t$ test to compare blood lactate before test with adjust and with 24 hours after the test. Mean and SD values were obtained for all descriptive variables. A $p$ value of $<0.05$ was considered significant. 


\section{Results}

According to Table 1, the analysis showed that there was a significant difference between blood lactate 30 minutes and just after the LTET $(p \leq 0.001)$ and between adjust and 24 hours after the LTET ( $p \leq 0.001)$. Blood lactate concentration decreased after interruption of the test and approximately returned to below the baseline level at 24 hours after the test.

Table 1. Blood Lactate concentration before and after Lactate Tolerance Swimming Test in elite boy swimmers

\begin{tabular}{|c|c|c|c|c|c|c|}
\hline & \multicolumn{2}{|c|}{$\begin{array}{l}30 \text { minutes before } \\
\text { competition }\end{array}$} & \multicolumn{2}{|c|}{ Just after competition } & \multicolumn{2}{|c|}{$\begin{array}{l}24 \text { hour after } \\
\text { competition }\end{array}$} \\
\hline & Mean & $\begin{array}{l}\text { Standard } \\
\text { Deviation }\end{array}$ & Mean & $\begin{array}{l}\text { Standard } \\
\text { Deviation }\end{array}$ & Mean & $\begin{array}{l}\text { Standard } \\
\text { Deviation }\end{array}$ \\
\hline $\begin{array}{l}\text { Blood lactate } \\
(\mathrm{mg} / \mathrm{dl})\end{array}$ & 30.35 & 12.16 & 108.52 & 18.17 & 26.51 & 8.57 \\
\hline
\end{tabular}

Table 2. Blood Lactate levels (mg/dl) in individual boy elite swimmers

\begin{tabular}{|c|c|c|c|c|}
\hline Record & $\begin{array}{l}30 \text { minutes before } \\
\text { lactate tolerance } \\
\text { exercise test }(1)\end{array}$ & $\begin{array}{c}\text { Just after lactate } \\
\text { tolerance exercise } \\
\text { test }(2)\end{array}$ & $\begin{array}{l}24 \text { hour after } \\
\text { lactate tolerance } \\
\text { exercise test ( } 3 \text { ) }\end{array}$ & $\begin{array}{c}\text { Different } \\
\text { between (1) and } \\
\text { (2) }\end{array}$ \\
\hline 1 & 26.44 & 136.63 & 24.85 & 110.19 \\
\hline 2 & 18.91 & 98.61 & 24.00 & 79.70 \\
\hline 3 & 32.9 & 86.88 & 21.20 & 53.98 \\
\hline 4 & 15.53 & 97.12 & 24.55 & 81.59 \\
\hline 5 & 35.44 & 128.53 & 23.05 & 93.09 \\
\hline 6 & 40.08 & 84.99 & 44.05 & 44.91 \\
\hline 7 & 26.43 & 109.19 & 19.15 & 82.76 \\
\hline 8 & 62.64 & 108.70 & 41.07 & 46.06 \\
\hline 9 & 27.06 & 88.90 & 18.75 & 61.84 \\
\hline 10 & 27.90 & 106.14 & 24.66 & 78.24 \\
\hline 11 & 23.15 & 125.35 & 18.78 & 102.20 \\
\hline 12 & 27.72 & 131.24 & 34.05 & 103.52 \\
\hline
\end{tabular}


The highest blood lactate levels were observed in swimmer number 8 and the lowest in swimmer number 4 who participated 30 minutes before lactate tolerance test (Table 2). Just after the test, the swimmer number 1 had the highest and number 3 showed the lowest blood lactate level. The swimmer number 8 and 11 had respectively the highest and the lowest blood lactate level at 24 hours after the test. The maximum different blood lactate level was observed for swimmer number 1 in the span of time of before and just after the test. On the contrary, the athlete number 6 had lowermost blood lactate different.

\section{Discussion}

During sports activities and physical exercise, sequences of physiological and biochemical changes happen, which reflect the stress of body under the load of training. For coaches and athletes, determining the load and duration of training has been scientifically a difficult problem for many years. When the training load and duration is larger than athletic abilities, it always causes injuries for athletes. On the contrary, too small loads fail to improve sports abilities and level effectively.

The production of lactate is believed to be augmented during exercise. This substrate diffuses from the muscle and accumulates in the blood. If the blood lactate is measured, it can serve as an indicator of activated processes during a workout. In light to moderate practices, the accumulation of lactate in the blood does not exist or is low. As the workload increases, blood lactate is also increased. However, blood PH is decreased when the level of lactate in muscles and blood goes up. Increment of blood PH may interfere with enzymatic activity of several glycolytic enzymes and actin-myosin interaction with the contractile process that may serve as a limiting function in exercises. Lactate has often used as an indicator of the intensity of exercise as well as the recovery from it.

We found that blood lactate level was significantly increased during LTET test. This result was similar to previous studies. Ikeda suggested that the twelve swims rushes with approximately 1 minute interval induced a significant increase in serum lactate (Ikeda, 2002). Mean blood lactate levels rose suddenly from an initial level of $1.34 \pm 0.35 \mathrm{~mm}$ before the first set to $12.28 \pm 1.55 \mathrm{~mm}$ after the first set. Then, lactate levels fell before rising again after the sets. Takagi et al suggested that the highest blood lactate levels were observed after the first trial set, they decreased significantly toward the second trial set, and were maintained at the same level after the third trial set (Takagi et al., 2013). Also, Kantanista et al (Kantanista et al., 2016) found that exercise increases blood lactate.

Contrary to our results, Melchorrim et al reported that mean blood lactate level was $7.7 \pm 1.0 \mathrm{~mm}$, and that blood lactate levels were $7.7 \pm 1.2,7.8 \pm 0.6,7.5 \pm 0.9$, 
and 7.2 $\pm 1.6 \mathrm{~mm}$ during the first, second, third, and fourth quarters, respectively (Melchiorri et al., 2010). Also, Vicente et al suggested that lactate concentration remained stable during half squat exercise at the lactate threshold among 13 healthy subjects (Garnacho-Castaño et al., 2015).

In our study the concentration of lactate in the blood achieved its below resting value after 24 hours of recovery. This data was in line with the findings of Degoutte et al (Degoutte et al., 2003), who observed that lactate concentrations in blood were appeared to return to the baseline level within 24 hours. Also, in study conducted by Kantanista blood lactate decreased after the interruption of exercise (Kantanista et al., 2016). Adversely, Jafari et al suggested that the blood lactate significantly increased 24 hours after 1600 meter running among 27 non athlete boys (Jafari et al., 2016). Other research (Ament et al., 1999) indicated that lactate still elevated after 30 minutes of recovery in healthy volunteers.

The investigators suggested a positive correlation between lactate production and average speed or distance of exercise (Avlonitou, 1996). Also, Benelli et al in 52 male swimmers aged 40-79 years suggested that the blood lactate is dependent to the intensity and distance of competition (Benelli et al., 2007). They stated that peaks of lactate were observed in distance of $100 \mathrm{~m}$. Also, Kantanista reported that by increasing the speed of the treadmill, blood lactate was increased (Kantanista et al., 2016).

Diet and nutritional status may stimuli strength and power adaptation (Crewther et al., 2006; Duke et al., 2011). Short-term diet modification has Influence on the blood lactate to rating of perceived exertion (Arshadi et al., 2017). The effect of sleep and sleep deprivation on cortisol and testosterone responses, anaerobic performance indices and blood lactate have been approved in active men (Sholi et al., 2015). We didn't evaluate these factors in present study. This can be seen as a limitation of our study. But blood sampling was drawn for participants 30 minutes and adjust after exertion and due to individual self-control, effect of these variables become disinterested.

\section{Conclusion}

We conducted an experiment to estimate lactate production during a lactate tolerance swimming test in swimming players. Our results showed a significant increase in blood lactate just after the test; and decreased to below of baseline 24 hours after the test. 


\section{Abbreviations}

ELIZA: Enzyme-Linked Immunosorbent Assay

L: Litter

LET: Lactate Tolerance Exercise Test

$\mathrm{Mg} / \mathrm{dl}$ : milligram/deciliter

mmol: millimole

REC: RECord

RF: Repetitions to Failure

RM: Repetition Max

RNF: Repetitions Not to Failure

SD: Standard Deviation

$\mu$ mol: micromole

\section{Acknowledgements}

We would like to thank the participants for the data sets. Special thanks to Jahrom University of Medical Sciences for the support on foundation.

\section{Author contribution}

Asghar Nikseresht: Design of study, proposal of study writing, final content of study Imman Yabande: proposal of study writing, enrolled data, manuscript writing Karamatollah Rahmanian: Design of study, proposal of study writing, analysis, interpretation, manuscript writing, final content of study

Abdolreza Sotoode Jahromi: proposal of study writing, interpretation, final content of study 


\section{References}

Aguiar, R.A., Cruz, R.S., Turnes, T., Pereira, K.L., and Caputo, F. (2015). Relationships between VO2 and blood lactate responses after all-out running exercise. Applied Physiology, Nutrition, and Metabolism 40, 263-268.

Altimari, J.M., Chacon-Mikahil, M.P.T., Pereira, L.A., Carneiro, J.G., Cyrino, E.S., and Altimari, L.R. (2010). Lactate minimum, anaerobic threshold and critical swimming speed in boys. Brazilian Journal of Sports and Exercise Research 1, 25-30.

Ament, W., Huizenga, J.R., Kort, E., van der Mark, T.W., Grevink, R.G., and Verkerke, G.J. (1999). Respiratory ammonia output and blood ammonia concentration during incremental exercise. Int J Sports Med 20, 71-77.

Arshadi, S., Banaeifar, A., Tabatabaey, H., and Shakibatabar, R. (2017). The Effect of Sleep and Sleep Deprivation on Cortisol and Testosterone Responses, Anaerobic Performance Indices and Blood Lactate in Active Men. www sjimu medilam ac ir 24, 66-76.

Avlonitou, E. (1996). Maximal lactate values following competitive performance varying according to age, sex and swimming style. The Journal of sports medicine and physical fitness 36, 24-30.

Baron, B., Dekerle, J., Depretz, S., Lefevre, T., and Pelayo, P. (2005). Self selected speed and maximal lactate steady state speed in swimming. The Journal of Sports Medicine and Physical Fitness 45, 1-6.

Beneke, R., Leithauser, R.M., and Ochentel, O. (2011). Blood lactate diagnostics in exercise testing and training. International Journal of Sports Physiology and Performance 6, 8-24.

Benelli, P., Ditroilo, M., Forte, R., De Vito, G., and Stocchi, V. (2007). Assessment of postcompetition peak blood lactate in male and female master swimmers aged 4079 years and its relationship with swimming performance. European Journal of Applied Physiology 99, 685-693.

Bonifazi, M., Sardella, F., and Lupo, C. (2000). Preparatory versus main competitions: differences in performances, lactate responses and pre-competition plasma cortisol concentrations in elite male swimmers. European Journal of Applied Physiology 82, 368-373.

Crewther, B., Keogh, J., Cronin, J., and Cook, C. (2006). Possible stimuli for strength and power adaptation. Sports medicine 36, 215-238.

Degoutte, F., Jouanel, P., and Filaire, E. (2003). Energy demands during a judo match and recovery. Br J Sports Med 37, 245-249.

Devlin, J., Paton, B., Poole, L., Sun, W., Ferguson, C., Wilson, J., and Kemi, O.J. (2014). Blood lactate clearance after maximal exercise depends on active recovery intensity. Journal of Sports Medicine and Physical Fitness 54, 271-278.

Duke, J., Lane, A., Behr, M., Ondrak, K., and Hackney, A. (2011). Exercise training biomarkers: Influence of short-term diet modification on the blood lactate to rating of perceived exertion (La: RPE) ratio. Acta Physiologica Hungarica 98, 128-136.

Garnacho-Castaño, M.V., Domínguez, R., Solano, P.R., and Mate-Munoz, J.L. (2015). Acute physiological and mechanical responses during resistance exercise executed at the lactate threshold workload. J Strength Cond Res 29, 2867-2873. 
Gorostiaga, E.M., Navarro-Amezqueta, I., Calbet, J.A.L., Sanchez-Medina, L., Cusso, R., Guerrero, M., Granados, C., Gonzalez-Izal, M., Ibanez, J., and Izquierdo, M. (2014). Blood Ammonia and Lactate as Markers of Muscle Metabolites During Leg Press Exercise. J Strength Cond Res 28, 2775-2785.

Hashimoto, T., and Brooks, G.A. (2008). Mitochondrial lactate oxidation complex and an adaptive role for lactate production. Sci Sports Exerc 40, 486-494.

Holfelder, B., Brown, N., and Bubeck, D. (2013). The Influence of Sex, Stroke and Distance on the Lactate Characteristics in High Performance Swimming. PloS one 8, e77185.

Ikeda, T. (2002). Changes of blood gas and serum lactate after interval training swimming underwater breath-hold (Rubicon Foundation).

Issurin, V.B., Kaufman, L.E., and Tenenbaum, G. (2001). Modeling of velocity regimens for anaerobic and aerobic power exercises in high-performance swimmers. J Sports Med Phys Fitness 41, 433-440.

Jafari, J., Kashef, M., and Gaeini, A.A. (2016). The Relationship between Blood Lactate and Albuminuria after Strenuous Activity in the Non-athlete Boys. International Journal of Health, Physical Education, and Computer Science in Sports 22, 32-34.

Kantanista, A., Kusy2, K., Zarębska, E., Włodarczyk, M., Ciekot-Sołtysiak, M., and Zieliński, J. (2016). Blood ammonia and lactate responses to incremental exercise in highly-trained male sprinters and triathletes. Biomedical Human Kinetics 8, 32-38.

Keskinen, O.P., Keskinen, K.L., and Mero, A.A. (2007). Effect of pool length on blood lactate, heart rate, and velocity in swimming. Int J Sports Med 28, 407-413.

LI, J. (2010). The Relations between Post-competition Blood Lactate and Achievement on Freestyle Swimmers. Hubei Sports Science 6.

Melchiorri, G., Castagna, C., Sorge, R., and Bonifazi, M. (2010). Game activity and blood lactate in men's elite water-polo players. J Strength Cond Res 24, 2647-2651.

Rogatzki, M.J., Wright, G.A., Mikat, R.P., and Brice, A.G. (2014). Blood Ammonium and Lactate Accumulation Response to Different Training Protocols Using the Parallel Squat Exercise. J Strength Cond Res 28, 1113-1118.

Sawka, M.N., Knowlton, R.G., Miles, D.S., and Critz, J.B. (1979). Post-competition blood lactate concentrations in collegiate swimmers. European Journal of Applied Physiology and Occupational Physiology 41, 93-99.

Sholi, S.G.A., Ghanbarzadeh, M., Habibi, A., and Ranjbar, R. (2015). Effects of aerobicresistance (concurrent) exercise intensities on serum levels of leptin, lactate, glucose and net protein in active men. Koomesh 17, 133-141.

Takagi, H., Murase, Y., Minami, T., Aoyagi, K., and Watanabe, Y. (2013). Lactate Production and Clearance During High Intensity Swimming Test in Elite Water-Polo Players. University of Tsukuba, School of Health and Sport Sciences 36, 77-84.

Vescovi, J.D., Falenchuk, O., and Wells, G.D. (2011). Blood lactate concentration and clearance in elite swimmers during competition. Int J Sports Physiol Perform 6, 106117.

Zaree, M., and Yarahmadi, H. (2013). Comparison of affect one session swimming, resistance and aerobic exercises on appetite, glucose and lactate in student girls. Journal of sabzevar university of medical sciences 20, 194-203. 